CASSOWARY volume 3 (2): 91-100

ISSN : 2614-8900

E-ISSN : 2622-6545

CProgram Pascasarjana Universitas Papua, https://pasca.unipa.ac.id/

\title{
Pertumbuhan Anggrek Grammatophyllum scriptum Asal Kultur In Vitro Pada Berbagai Macam Formulasi Media Tumbuh Berbasis Ampas Sagu
}

\author{
(The Growth of Orchid (Grammatophyllum Scriptum) In Vitro Culture on Various Growth \\ Medium Formulation Based On Sago Dregs)
}

\section{Zarima Wibawati*, Amelia Sarungallo, Barahima Abbas}

Program Studi Agroteknologi, Jurusan Budidaya Pertanian, Fakultas Pertanian

Universitas Papua, J1. Gunung Salju Amban Manokwari, 98314, Indonesia

*Email: zarimawibawati03@gmail.com

\begin{abstract}
ABSTRAK: Tanaman anggrek merupakan salah satu tanaman yang termasuk dalam family Orchidaceae. Tanaman ini merupakan bunga potong yang banyak disukai selain mawar dan melati. Pengembangbiakan anggrek secara alami menggunakan biji sangat sulit karena anggrek mempunyai laju pertumbuhan dari fase biji hingga mencapai tanaman dewasa yang sangat lambat, sehingga dapat diperbanyak menggunakan teknik kultur jaringan. Perbanyakan dengan teknik kultur jaringan menggunakan biji akan menghasilkan tanaman anggrek lebih banyak, membutuhkan waktu yang singkat dan bebas dari hama penyakit. Tingkat keragaman dari tanaman anggrek hasil kultur jaringan dapat ditentukan melalui pengukuran karakter morfologi. Tanaman anggrek juga dapat dilihat dari pertumbuhannya dengan berbagai macam formulasi media tumbuh. Jenis media yang baik digunakan untuk pertumbuhan anggrek adalah jenis media tanam yang memiliki kemampuan menyimpan air dan hara yaitu cocopeat dan ampas sagu. Penggunaan jenis media formulasi ampas sagu masih minim. Oleh karena itu, penelitian yang mengkaji pertumbuhan tanaman anggrek perlu dilakukan. Penelitian ini bertujuan untuk mengukur pertumbuhan vegetatif $G$. scriptum pada berbagai macam formulasi media tumbuh berbasis ampas sagu secara in vitro. Penelitian ini dilaksanakan selama 8 bulan yaitu dari bulan Maret sampai bulan Oktober 2018 di Laboratorium Bioteknologi Fakultas Pertanian dan Screen House Universitas Papua. Berdasarkan hasil penelitian dapat disimpulkan bahwa: (a) Pertumbuhan tanaman anggrek hingga 8 bulan pengamatan terhadap variabel jumlah daun dan jumlah anakan tidak berbeda nyata, (b) Media ampas sagu + kompos (P2) merupakan media yang dapat menginduksi pertumbuhan jumlah daun tanaman anggrek terbanyak, (c) Media ampas sagu + pupuk kandang (P1) dan ampas sagu + kompos (P2) merupakan media yang menginduksi munculnya anakan pada anggrek $\mathrm{G}$. scriptum paling cepat.
\end{abstract}

Kata kunci : Grammatophyllum scriptum; kultur in vitro; jenis media,

\section{PENDAHULUAN}

Anggrek merupakan salah satu tanaman hortikultura yang banyak diminati karena keindahan bunganya.
Anggrek termasuk dalam famili Orchidaceae. Famili ini merupakan famili bunga-bungaan yang paling besar dan banyak digunakan sebagai bunga 
potong. Di Indonesia banyak jenis tumbuhan yang termasuk dalam tumbuhan epifit. Tumbuhan epifit adalah tumbuhan yang hidupnya menempel pada tumbuhan inang, salah satunya adalah anggrek. Spesies anggrek yang ada di Indonesia mempunyai potensi yang dapat dipakai sebagai induk silang dan unggul (Sandra, 2003).

Indonesia memiliki keragaman spesies anggrek yang banyak yaitu sekitar 5000 spesies yang tersebar di hutan-hutan Indonesia. Kelestarian keanekaragaman anggrek mulai terancam akibat banyaknya penebanganpenebangan liar yang tidak bertanggung jawab dan menyebabkan beberapa spesies anggrek terancam punah, salah satunya yaitu anggrek Grammatophyllum scriptum. Untuk menghindari adanya kepunahan harus dilakukan pelestarian. Salah satu cara untuk melestarikan yaitu dengan melakukan perbanyakan (Lestari et al., 2013).

Grammatophyllum merupakan salah satu jenis tanaman anggrek yang memiliki beberapa jenis yaitu Grammatophyllum scriptum, Grammatophyllum speciosum dan Grammatophyllum stapeliaeflorum, yang paling terkenal adalah anggrek Grammatophyllum scriptum. Anggrek ini paling terkenal di daerah Papua dan Maluku dengan sebutan anggrek macan (Shalifah, 2011).

\section{Anggrek Grammatophyllum} scriptum memiliki potensi yang besar dalam bidang bisnis. Potensi produksi anggrek ini lebih tinggi jika di bandingkan dengan tanaman hias lainnya. Produksi anggrek pada tahun 2015 sebesar 21.514 .789 tangkai dan pada tahun 2016 produksi tanaman anggrek mengalami penurunan yaitu sebesar 19.978.078 tangkai (BPS, 2016).

Anggrek mempunyai peran penting dalam bidang pertanian, yaitu nilai ekonomi yang tinggi serta warna bunga yang menarik dan bentuknya unik, sehingga mempunyai daya tarik sendiri. Widiastoety et al., (2010) menyatakan bahwa anggrek banyak diminati oleh konsumen dari dalam negeri maupun dari luar negeri, karena keunikan karakter yang khas dapat menjadikan anggrek dalam rangkaian bunga potong yang tidak dapat digantikan oleh bunga lain. Daya tahan kesegaran bunga yang dimiliki anggrek termasuk dalam daya tahan yang begitu lama jika di bandingkan dengan bunga potong lainnya seperti mawar, anyelir dan gladiol.

Banyak konsumen yang tertarik pada anggrek karena anggrek ini sangat mudah beradaptasi di dataran rendah, perawatannya tidak terlalu sulit walaupun anggrek tumbuh dengan lambat, dan mudah berbunga jika dibandingkan dengan jenis tanaman lainnya. Jika tanaman anggrek Grammatophyllum scriptum sudah berbunga maka keindahan dari anggrek ini sudah dapat dinikmati oleh banyak konsumen (Suradinata et al., 2016). Keistimewaan anggrek Grammatophyllum scriptum yaitu mempunyai warna dasar hijau dengan totol - totol coklat yang mirip seperti warna macan dan memiliki habitus yang tegap dan kuat (Markal et al., 2015).

Menurut Isda et al., (2014), pengembangbiakan anggrek secara alami menggunakan biji sangat sulit karena anggrek mempunyai laju pertumbuhan dari fase biji hingga mencapai tanaman dewasa yang sangat lambat. Perbanyakan secara konvesional untuk memenuhi kebutuhan bibit yang banyak dengan waktu yang cepat sulit dicapai, sehingga menyebabkan anggrek ini merupakan salah satu plasma nutfah yang dilindungi. 


\section{Permasalahan}

Biji anggrek dapat dikembangkan menggunakan metode kultur jaringan dengan tingkat keberhasilan yang tinggi. Tanaman yang dihasilkan melalui kultur jaringan disebut planlet. Planlet hasil kultur jaringan tidak dapat ditanam langsung dilapang. Sebelum ditanam dilapang terlebih dahulu perlu melalui proses adaptasi yang disebut dengan proses aklimatisasi. Bibit yang telah mengalami proses aklimatisasi dapat ditanam langsung dilapang dengan mengoptimalkan pertumbuhan melalui perbaikan kondisi media tanam.

Pertumbuhan dan perkembangan anggrek yang baik sangat dipengaruhi oleh medianya. Jenis media yang dapat digunakan berupa ampas sagu, moss, pakis, cocopeat dan sekam sudah banyak digunakan karena terbukti dapat mendorong pertumbuhan yang baik (Sandra, 2003).

Jenis media yang baik digunakan untuk pertumbuhan anggrek adalah jenis media tanam yang memiliki kemampuan menyimpan air dan hara seperti cocopeat. Jenis media tanam yang baik dapat ditentukan apabila mampu mengoptimalkan pertumbuhan tunas dan dapat memperbanyak jumlah tunas (Wardani et al., 2011). Selain jenis media cocopeat, ampas sagu juga dapat menyimpan air dan hara yang baik, dan memiliki unsur hara yang sangat dibutuhkan untuk pertumbuhan anggrek. Komposisi media tanam yang baik untuk pertumbuhan bibit anggrek yang telah mengalami aklimatisasi perlu dikaji agar dapat mendorong pertumbuhan yang optimal, salah satu caranya media tanam yang mampu menyimpan air dan mampu memberikan hara pada tanaman anggrek, salah satu media tumbuhan yang dapat memperlihatkan kecambah dan hara adalah ampas sagu. Formula campuran ampas sagu dengan kompos media organik lainnya perlu dikaji. Kajian tentang media tanam ampas sagu pada tanaman anggrek masih kurang termasuk formulasi dengan media organik lainnya. Melalui penelitian ini akan dibagi media taman ampas sagu dan formulasinya dengan media organik lain untuk pertumbuhan anggrek G. scriptum.

\section{Tujuan dan Manfaat}

Penelitian ini bertujuan untuk: (1) mengukur pertumbuhan vegetatif $G$. scriptum pada berbagai macam formulasi media tumbuh berbasis ampas sagu secara in vivo.

Penelitian ini bermanfaat sebagai sumber informasi berbagai macam formulasi media tanam yang sesuai untuk pertumbuhan anggrek $G$. scriptum secara in vivo.

\section{Hipotesis}

1. Pertumbuhan anggrek G. scriptum pada berbagai media tumbuh berbasis ampas sagu bervariasi.

\section{METODE PENELITIAN}

\section{Waktu dan Tempat}

Penelitian ini dilaksanakan selama 8 bulan yaitu dari bulan Maret sampai bulan Oktober 2018 di Laboratorium Bioteknologi Fakultas Pertanian dan Screen House Universitas Papua. Analisis keragaman genetik dilaksanakan pada bulan Maret 2019 di Laboratorium Biologi Molekuler BB Biogen, Bogor.

\section{Bahan dan Alat Bahan}

Bahan yang digunakan dalam penelitian ini adalah anggrek Grammatophyllum scriptum, air, ampas sagu, pupuk kompos, pupuk kandang kambing, dan sabut kelapa.

\section{Alat}

Alat-alat yang digunakan dalam penelitian ini adalah bolpen, buku, pot, sarung tangan, kamera, dan gembor. 


\section{Rancangan Penelitian}

Penelitian ini merupakan percobaan satu faktor yang dirancang dengan Rancangan Acak Lengkap. Perlakuan adalah jenis media tanam yang meliputi ampas sagu (P0), pupuk kandang kambing (P1), kompos (P2), dan cocopeat (P3). Setiap perlakuan diulang 4 kali sehingga diperoleh 16 satuan percobaan.

\section{Pelaksanaan Penelitian}

\section{Persiapan Bahan Tanaman}

Anggrek Grammatophyllum srciptum yang digunakan pada penelitian ini adalah hasil kultur in vitro yang menggunakan eksplan biji. Planlet hasil kultur in vitro yang telah mengalami aklimatisasi digunakan sebagai bahan tanaman untuk analisis keragaman genetik dan untuk mengevaluasi pertumbuhannya berbagai macam formulasi media tanam pada kondisi in vivo.

\section{Persiapan media tanam}

Media tanam yang digunakan terdiri atas campuran ampas sagu, pupuk kandang, kompos, dan cocopeat. Media tanam dicampur sesuai dengan perbandingan dalam ukuran volume sebagai berikut :

P0 : Ampas sagu

P1 : Ampas sagu + pupuk kandang, dengan perbandingan $1: 1$

P2 : Ampas sagu + kompos, dengan perbandingan 1:1

P3 : Ampas sagu + cocopeat, dengan perbandingan 1:1.

Masing-masing media beratnya $400 \mathrm{~g}$. Media yang telah siap dimasukkan ke dalam pot yang telah disediakan.

\section{Persiapan Bibit dan Penanaman}

Bibit yang digunakan adalah bibit anggrek Grammatophyllum scriptum hasil kultur im vitro yang telah mengalami aklimatisasi. Bibit anggrek dipindahkan dari media tanam serabut kelapa dan ditanam ke media tanam yang telah disiapkan. Bibit yang digunakan adalah bibit yang telah memiliki 3 helai daun. Penanaman dilakukan dengan cara membuat lubang tanaman kemudian bibit yang telah dipisahkan dari rumputnya di tanam pada media yang telah di siapkan.

\section{Pemeliharaan}

Pemeliharaan yang dilakukan pada tanaman anggrek diantaranya yaitu penyiraman dan pengendalian hama. Penyiraman dilakukan 2 kali sehari pada pagi dan sore hari dengan menggunakan gembor pada setiap media. Apabila hujan, maka tidak dilakukan penyiraman. Pengendalian hama dilakukan dengan cara manual, yaitu dengan cara mengusir dan membunuh serangga atau hama yang menyerang tanaman anggrek.

\section{Variabel Pengamatan}

Variabel yang diamati dalam penelitian ini terdiri dari :

1. Jumlah daun

Jumlah daun yang dihitung adalah daun yang terbentuk sempurna dan masih hijau. Pengamatan dilakukan setiap satu bulan sekali.

2. Umur muncul anakan

Umur muncul anakan diamati pada saat mulai anakan tumbuh pada setiap media.

\section{Analisis Data \\ Data hasil pengukuran pertumbuhan $G$. scriptum dianalisis secara statistik dengan menggunakan ANOVA yang dikalkulasi dengan menggunakan Minitab 17.}


HASIL

\section{Pertumbuhan G. scriptum pada Media Berbasis Ampas Sagu}

Rata-rata pertumbuhan jumlah daun anggrek $G$. scriptum yang ditumbuhkan pada media berbasis ampas sagu disajikan pada Tabel 2. Jumlah daun yang terbentuk paling banyak yaitu pada perlakuan ampas sagu + kompos dengan perbandingan 1:1 yang terdapat pada sampel P2.
Berdasarkan Tabel 2, rata-rata jumlah daun tanaman anggrek $G$. scriptum setiap bulannya mengalami kenaikan setiap bulannya, namun ada beberapa sampel yang mengalami penurunan jumlah daunnya pada pengamatan umur ketujuh dan kedelapan setelah tanam. Rata-rata jumlah daun yang paling banyak terdapat pada sampel P2 yaitu sebanyak 10,25, sedangkan yang paling sedikit terdapat pada semua sampel anggrek yaitu sebanyak 3,00 diumur satu bulan setelah tanam.

Tabel 1. Rata-rata jumlah daun anggrek G. scriptum berdasarkan media tanam pada umur 1 sampai 8 BST

\begin{tabular}{ccccccccc}
\hline \multirow{2}{*}{ Perlakuan } & \multicolumn{7}{c}{ Umur (Bulan Setelah Tanam) } \\
\cline { 2 - 9 } & 1 & 2 & 3 & 4 & 5 & 6 & 7 & 8 \\
\hline P0 & 3,00 & 3,50 & 4,50 & 5,00 & 6,50 & 7,75 & 9,00 & 8,50 \\
P1 & 3,00 & 3,75 & 4,50 & 5,00 & 6,50 & 8,50 & 9,50 & 9,25 \\
P2 & 3,00 & 3,50 & 4,25 & 5,00 & 7,00 & 8,50 & 10,25 & 8,50 \\
P3 & 3,00 & 4,00 & 4,50 & 5,25 & 7,50 & 8,75 & 9,50 & 8,50 \\
\hline
\end{tabular}
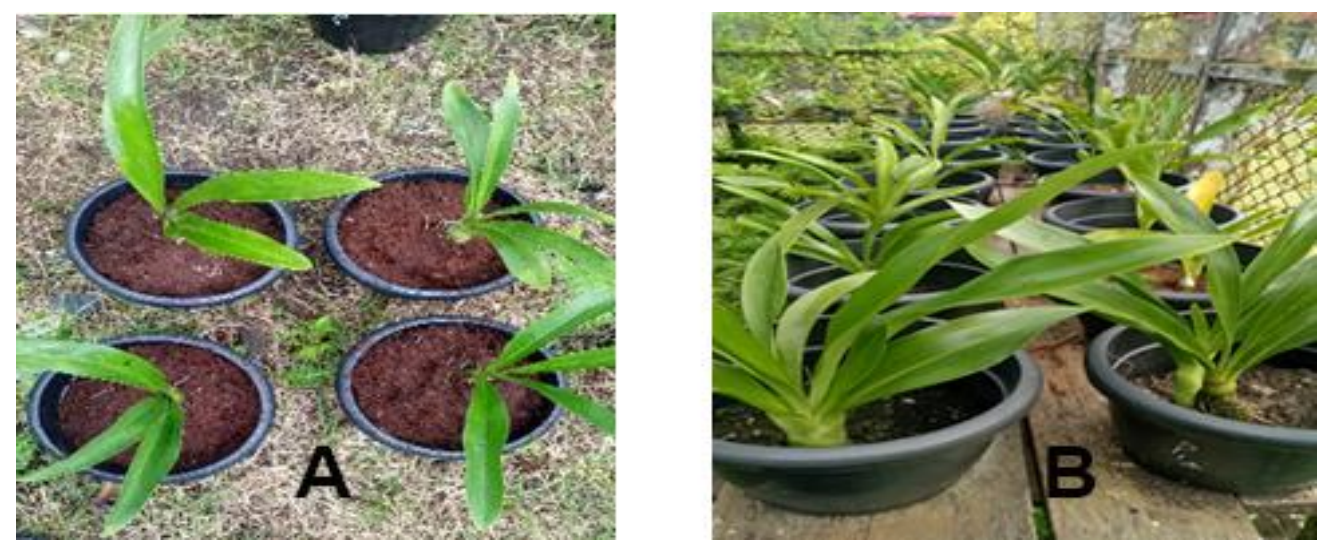

Gambar 1. Penampilan pertumbuhan tanaman anggrek G. scriptum pada saat umur 2 BST (A) dan 5 BST (B)

Tabel 2. Hasil analisis ragam jumlah daun anggrek G. scriptum umur 1 sampai 8 BST

\begin{tabular}{ccccccccc}
\hline \multirow{2}{*}{ SK } & \multicolumn{7}{c}{ Umur (Bulan Setelah Tanam) } \\
\cline { 2 - 9 } & 1 & 2 & 3 & 4 & 5 & 6 & 7 & 8 \\
\hline JK & 0 & 0,688 & 0,188 & 0,688 & 2,750 & 2,250 & 3,188 & 1,688 \\
KT & 0 & 0,229 & 0,063 & 0,229 & 0,917 & 0,750 & 1,063 & 0,563 \\
F $_{\text {Hit }}$ & 0 & 0,579 & 0,097 & 0,200 & 0,647 & 0,783 & 1,000 & 0,113 \\
Sig. & 0 & 0,640 & 0,960 & 0,894 & 0,600 & 0,526 & 0,426 & 0,951 \\
\hline & tn & tn & tn & tn & tn & tn & tn & tn
\end{tabular}

Keterangan : SK (Sumber Keragaman); JK (Jumlah Kuadrat); KT (Kuadrat Tengah); $F_{\text {Hit }}(\mathrm{F}$ Hitung); Sig. (Signifikan); dan tn (Tidak Nyata) 


\section{Rata-rata Jumlah Daun}

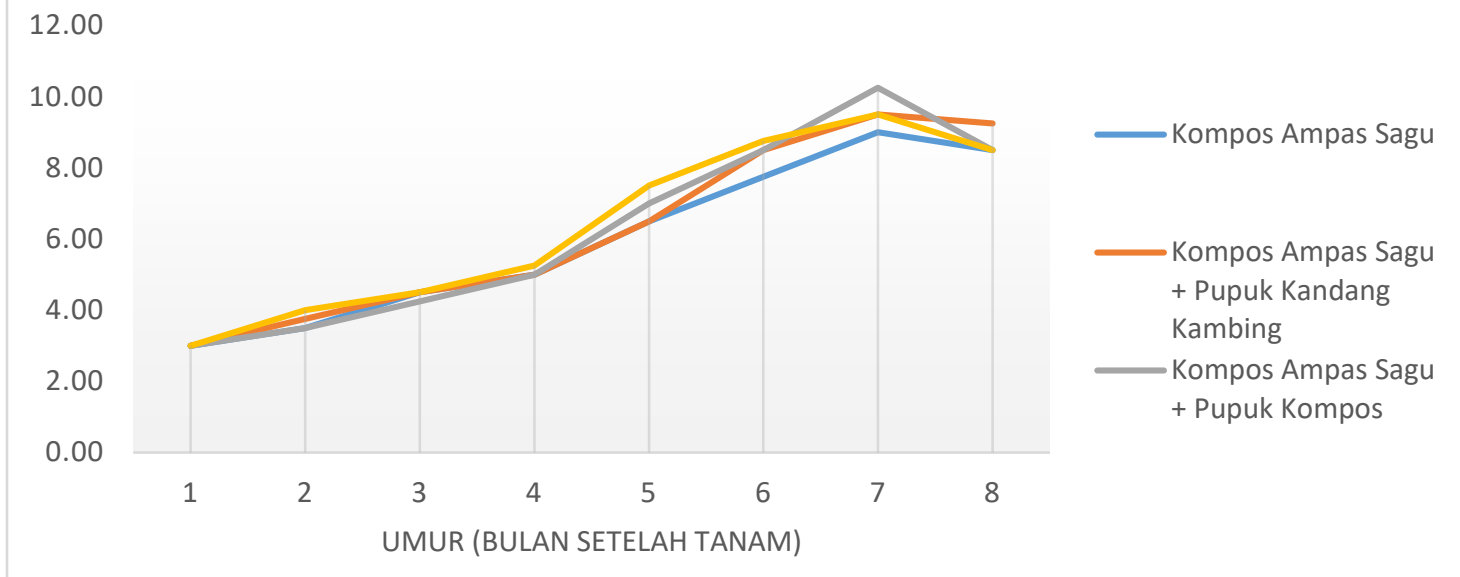

Gambar 2. Grafik perkembangan jumlah daun pada berbagai macam media tanam pada umur 1 sampai 8 BST

Berdasarkan Tabel 2 hasil analisis ragam menunjukan bahwa perlakuan media tanam tidak berpengaruh nyata terhadap jumlah daun pada umur 1 sampai 8 BST.

Grafik perkembangan jumlah daun anggrek pada berbagai media tanam disajikan pada Gambar 4. Grafik ini memperlihatkan pola yang sama pada perkembangan jumlah daun tanaman anggrek untuk semua jenis media yaitu terjadi peningkatan selama masa pertumbuhan dari tanaman anggrek tersebut. Perkembangan jumlah daun yang paling rendah terpadat pada jenis media ampas sagu (P0).

\section{PEMBAHASAN}

\section{Pertumbuhan G. scriptum pada Media Berbasis Ampas Sagu}

Peningkatan volume jaringan atau organ akibat adanya pembelahan dan pemanjangan sel yang bersifat irreversible disebut pertumbuhan. Menurut Alnopri (2004) mengatakan bahwa respon pertumbuhan tanaman merupakan hasil dari interaksi antara dua faktor, yaitu faktor genetik dan faktor lingkungan. Komponen jumlah daun pada tanaman anggrek yang ditanam pada berbagai macam media ampas sagu menunjukkan adanya peningkatan setiap bulannya, namun terjadi penurunan diakhir pengamatan pada penelitian ini. Hal ini disebabkan karena beberapa daun tanaman anggrek terkena penyakit sehingga lama kelamaan daun menjadi menguning dan kering sehingga daun menjadi gugur. Pada penelitian ini daun yang dihitung adalah daun yang baru muncul atau daun yang masih segar. Pada tanaman anggrek daun sangat penting untuk termpat terjadinya fotosintesis. Jika jumlah daun semakin banyak dan ukurannya semakin besar maka fotosintesis yang terjadi akan optimal. Pada kondisi tersebut juga fotosintat dalam jumlah yang tinggi sehingga dapat memacu pertumbuhan dan meningkatkan produksi biomasa. Hal ini sesuai dengan hasil penelitian Nugraha et al., (2014) yang menyatakan bahwa dengan cukupnya ketersediaan hara, maka fotosintesis akan berlangsung dengan baik dan fotosintat yang dihasilkan akan lebih banyak dan dapat digunakan untuk pembentukan daun. Pendapat tersebut juga sesuai dengan penelitian Sudrajat et al., (2013) dan Nasution (2010) yang menyatakan bahwa karakter jumlah daun berkolerasi positif terhadap karakter pertumbuhan dan produksi tanaman.

Faktor lain yang dapat menyebabkan terjadinya peningkatan 
jumlah daun tanaman anggrek yaitu tercukupinya kebutuhan unsur hara dan air. Unsur hara diperoleh dari lingkungannya atau media tanam yang digunakan. Jenis media tanam yang digunakan dalam penelitian ini adalah ampas sagu, pupuk kandang, kompos, dan cocopeat. Menurut penelitian Uruilal et al., (2012) menyatakan bahwa kandungan yang terdapat pada kompos ampas sagu terdiri dari $10,17 \%$ karbohidrat, $0,64 \%$ N, 0,2\% P dan 1,44\% $\mathrm{K}$. Kandungan hara pupuk kandang kambing antara lain $31 \%$ bahan organik, $0,7 \%$ nitrogen, $0,4 \% \mathrm{P}_{2} \mathrm{O}_{5}, 0,25 \% \mathrm{~K}_{2} \mathrm{O}$, dan $0,4 \% \mathrm{CaO}$. Menurut penelitian Baroroh (2016) mengatakan bahwa kandungan yang terdapat pada pupuk kompos adalah $\mathrm{C}$ organik $=27,79 \%$; bahan organik $=47,91 \% ; \mathrm{N}=2,73 \%$; $\mathrm{P} 2 \mathrm{O} 5=1,95 \%$; $\mathrm{K} 2 \mathrm{O}=1,88 \%$; $\mathrm{C} / \mathrm{N}$ rasio $=10,18$ dan kadar air $=24,44 \%$.

Ketersediaan air bagi tanaman anggrek juga sangat dibutuhkan untuk kelangsungan hidupnya, karena air sangat penting dan tidak bisa dgantikan oleh senyawa lainnya. Salah satu komponen penyusun sel adalah air. Jika tanaman kekurangan air maka turgor sel yang ada di tanaman akan mengalami penurunan. Penurunan turgiditas sel terutama pada sel stomata akan mengahambat fiksasi $\mathrm{CO}_{2}$ sehingga kekurangan air dapat menghambat laju fotosintesis (Lakitan, 2011).

Salah satu upaya untuk menjaga ketersediaan air bagi tanaman maka dapat melakukan penyiraman. Penyiraman juga menentukan jumlah air yang tersedia dan dapat dimanfaatkan oleh tanaman anggrek. Tanaman anggrek termasuk dalam tipe higrofit, sehingga tanaman anggrek dapat mampu hidup di tempat yang lembab yang tidak terlalu banyak membutuhkan air sehingga dapat menghasilkan pertumbuhan yang optimal. Penyiraman tanaman anggrek setiap bulan dilakukan seminggu dua kali. Meskipun frekuensi untuk penyiraman tanaman anggrek belum optimal, namun berdasarkan respon jumlah daun tanaman anggrek cukup baik karena telah mampu memenuhi kebutuhan bibit anggrek. Menurut Setiawan et al., (2013) mengatakan bahwa tanaman yang mengalami kekurangan air maka akan terjadi penurunan konduktivitas stomata, laju tranpirasi dan kandungan air nisbi.

Respon pertumbuhan jumlah daun pada setiap tanaman menunjukkan hasil yang bervariasi, meskipun berada dalam lingkungan yang seragam. Variabel jumlah daun pada penelitian menunjukan tanaman anggrek memiliki nilai jumlah daun terbanyak dan ada pula jumlah daun yang sedikit.

Berdasarkan hasil analisis statistik anggrek G. scriptum dan media tanam terhadap jumlah daun, dimana rata-rata jumlah daun tanaman anggrek $G$. scriptum cenderung mengalami kenaikan setiap bulannya, namun ada beberapa sampel yang mengalami penurunan di umur delapan bulan setelah tanam. Jumlah daun terbanyak terdapat pada sampel ampas sagu + kompos (P2) yaitu sebanyak 10,25. Hal ini disebabkan karena kompos ampas sagu + kompos merupakan jenis media yang memiliki aerasi yang baik, dapat mengikat air serta unsur hara yang baik jika di bandingkan dengan jenis media lainnya. Hal ini sesuai dengan penelitian Riyanto (2016) yang mengatakan bahwa unsur hara yang terkandung dalam ampas sagu diduga mampu mencukupi kebutuhan bibit sehingga proses pertumbuhannya tidak mengalami penghambatan. Hal ini juga sesuai dengan penelitian Wardani et al., (2013), yang mengatakan bahwa media yang terbaik dalam tahap aklimatisasi pada anggrek adalah cocopeat yang memiliki kemampuan menyimpan air dan hara dengan baik. Keunggulan media tersebut dapat dilihat dari 
banyaknya jumlah daun. Morfologi tanaman anggrek yang mana jumlah daun terbanyak ditentukan oleh banyaknya ruas dan tinggi tanaman. Irwanto (2003) mengatakan bahwa terjadinya penambahan jumlah daun pada suatu tanaman dapat disebabkan karena adanya peristiwa pembelahan dan perpanjangan sel yang didominasi dibagian ujung pucuk. Sedangkan jumlah daun sedikit dapat disebabkan karena penyiraman yang dilakukan tidak teratur yang menyebabkan tanaman kekurangan air sehingga daunnya menjadi berkurang. Hal ini sesuai dengan penelitian Mapegau (2006), bahwa pengaruh cekaman kekurangan air pada pertumbuhan tanaman dicerminkan oleh daun-daun yang lebih kecil dan menjadi gugur.

Berdasarkan hasil analisis ragam pada penelitian menunjukkan bahwa anggrek $G$. scriptum tidak berbeda nyata terhadap jumlah daun dan jenis media yang digunakan. Hal ini disebabkan karena penyiraman yang dilakukan pada tanaman anggrek terlalu banyak air sehingga media yang digunakan menjadi basah yang menyebabkan tanaman menjadi layu dan membusuk. Selain itu juga karena perbandingan perlakuan yang diberikan kepada tanaman anggrek kurang signifikan sehingga campuran unsur hara yang ada masih kurang. Tanaman anggrek membutuhkan campuran media yang mempunyai unsur hara cukup sehingga menghasilkan pertumbuhan yang baik. Pendapat ini di dukung oleh Ginting (2008) yang menyatakan bahwa penggunaan media campuran dengan perlakuan berbeda akan menghasilkan pertumbuhan anggrek yang lebih baik jika dibandingkan dengan media tunggal atau perlakuan yang sama. Hal ini sesuai dengan penelitian Supriyadi (2001) yang menyatakan bahwa tanaman yang diberi pupuk daun menghasilkan jumlah daun lebih banyak dibandingkan tanpa pupuk.

Pada penelitian ini media tanam ampas sagu + kompos merupakan media terbaik pada pertumbuhan anggrek $G$. scriptum berdasarkan hasil statistik pada rata-rata jumlah daun. Hal ini sesuai dengan hasil penelitian Muhit (2007) yang mengatakan bahwa pada tanaman anggrek bulan yang menunjukan bahwa media campuran kompos menghasilkan pembesaran bibit kompot anggrek bulan yang lebih baik jika dibandingkan dengan media lainnya.

Umur anakan yang muncul pada tanaman anggrek berbeda-beda setiap jenis media yang digunakan. Rata-rata anakan muncul pada 2 bulan setelah tanam yaitu pada media ampas sagu + pupuk kandang (P1) dan ampas sagu + kompos (P2), sedangkan ampas sagu dan ampas sagu + cocopeat (P3) anakan muncul pada 3 bulan setelah tanam.

\section{Simpulan}

1. Pertumbuhan tanaman anggrek hingga 8 bulan pengamatan terhadap variabel jumlah daun dan jumlah anakan tidak berbeda nyata.

2. Media ampas sagu $+\operatorname{kompos}(\mathrm{P} 2)$ merupakan media yang dapat menginduksi pertumbuhan jumlah daun tanaman anggrek terbanyak.

3. Media ampas sagu + pupuk kandang (P1) dan ampas sagu + kompos (P2) merupakan media yang menginduksi munculnya anakan pada anggrek $G$. scriptum paling cepat.

\section{Saran}

1. Perlu dilakukan penelitian lebih lanjut dengan menggunakan komposisi media dan tanaman anggrek endemik Papua lainnya. 
DAFTAR PUSTAKA

Alnopri. 2004. Variabilitas genetik dan heritabilitas sifat-sifat pertumbuhan bibit tujuh genotipe kopi robusta-arabika. Jurnal Ilmu-Ilmu Pertanian Indonesia 6(2): 91-96.

BPS. 2016. Tanaman Hias Indonesia. Produksi Anggrek Indonesia 2015-2016.

Baroroh, A. 2016. Analisis Kandungan Unsur Hara Makro Pada Pupuk Kompos Dari Serasah Daun Bambu dan Limbah Padat Pabrik Gula (Blotong). [Skripsi] Fakultas MIPA Universitas Sebelas Maret.

Ginting, B., W. Prasetio, dan T. Sutater. 2001. Pengaruh cara pemberian air, media dan pemupukan terhadap pertumbuhan anggrek Dendrobium sp. J.Hort. 11(1) : 22-29.

Hartati, S. 2015. Analisis keragaman genetik tetua dan hasil persilangan anggrek hitam (Coelogyne pandurata Lindl.). [Disertasi] Program Doctor Ilmu Pertanian Universitas Sebelas Maret Surakarta.

Irwanto. 2003. Pengaruh Hormon IBA (Indole Butyric Acid) Terhadap Keberhasilan Stek Gotasia. http://www. Irwantoshut.com. Diakses tanggal 17 Mei 2019.

Isda, M. N. dan S. Fatonah. 2014. Induksi akar pada eksplan tunas anggrek Grammatophylum scriptum var. Citirum secara in vitro pada media ms dengan penambahan NAA dan BAP. Jurnal Biologi 7(2): 53-57.
Lakitan, B. 2011. Dasar-Dasar Fisiologi Tumbuhan. PT. Raja Grafindo Persada. Jakarta. 205p.

Lestari, E., T. Nurhidayati, dan S. Nurfadilah. 2013. Pengaruh konsentrasi ZPT 2,4-D dan BAP terhadap pertumbuhan dan perkembangan biji Dendrobium laxidlorum J.J Smith secara in vitro. Jurnal Sains dan Seni Pomits 2(1): 2337-3250.

Mapegau. 2006. Pengaruh cekaman air terhadap pertumbuhan dan hasil tanaman kedelai. Jurnal Ilmiah Pertanian Kultura 41 (1): 43-48.

Markal, A., M. N. Isda, dan S. Fatonah. 2015. Perbanyakan anggrek Grammatophylum scriptum (Lindl.) BL. melalui induksi tunas secara in vitro dengan penambahan BAP dan NAA. Jurnal FMIPA 2(1): 108-114.

Muhit, A. 2007. Teknik Penggunaan Beberapa Jenis Media Tanaman Alternatif dan Pengatur Tumbuh Pada Kompo Anggrek Bulan. Balai Penelitian Tanaman Hias. Cianjur.

Nasution, M. A. 2010. Analisis korelasi dan sidik lintas antara karakter morfologi dan komponen buah tanaman nanas (Ananas comosus L. Merr). Crop Agro 3(1): 1-9.

Nugraha, Y. S., T. Sumarni, dan Roedy Sulistyono. 2014. Pengaruh interval waktu dan tingkat pemberian air terhadap pertumbuhan dan hasil tanaman kedelai (Glycine $\max$ (L) 
Merill.). Jurnal Produksi Tanaman 2(7): 552-559.

Riyanto. 2016. Respon Pertumbuhan dan Keragaman Genetik Bibit Sagu Asal Biji. [Skripsi] Fakultas Pertanian Universitas Papua.

Sandra, E. 2003. Kultur Jaringan Anggrek Skala Rumah Tangga. AgroMedia Pustaka. Bogor.

Setiawan, T. dan D. Shiddieq. 2013. Pengaruh cekaman kurang air terhadap beberapa karakter fisiologi tanaman nilam (Pogostemon cablin Benth). Jurnal Littri 19(3): 108-116.

Shalifah, H. A. B., Muskhazli, Rusea, dan Nithiyaa. 2011. Variation in Mycorrhizal Specificity for In Vitro Symbiotic Seed Germination of Grammatophyllum speciosum Blume. Sains Malaysiana 40(5): 451-455.

Sudrajat, D. J., I. Z. Siregar, N. Khumaidi, U. J. Siregar, dan I. Mansur. 2013. Keragaman antar populasi dan korelasi antar karakter bibit jabon putih (Neolamarckia cadamba (Roxb.) Bosser) pada cekaman kekeringan dan genangan air. Jurnal Penelitian Kehutanan Wallacea 5(1): 13-24.

Supriyadi, L. 2001. Pengaruh Pemberian Pupuk Mg terhadap Pertumbuhan Lidah Buaya (Aloe Vera linn) yang Ditanam pada Beberapa Perimbangan Dosis Pupuk N dan K. Skripsi. Jurusan Budidaya Pertanian, Fakultas Pertanian. Institut Pertanian Bogor. 30 hal.
Suradinata, Y. R., A. Nuraini, dan A. Sela. 2016. Respon bunga anggrek Dendrobium F1 (Dendrobium Malaysian Green) pada berbagai konsentrasi giberelin. Jurnal Kultivasi 15(1): 1-7.

Urailal, C., A. M. Kalay, E. Kaya, dan A. Siregar. 2012. Pemanfaatan ela sagu, sekam dan dedak sebagai media perbanyakan agens hayati Trichoderma harzianum Rifai. Agrologia 1(1): 21-30.

Wardani, Sri., H. Setiado, dan S. Ilyas. 2011. Pengaruh media tanam dan pupuk daun terhadap aklimatisasi anggrek Dendrobium sp. Jurnal Pertanian Kultivar 5(1): 11-18.

Widiastoety, D., N. Solvia, dan M. Soedarjo. 2010. Potensi anggrek Dendrobium sp dalam meningkatkan variasi dan kualitas anggrek bunga potong. Jurnal Litbang Pertanian 29(3): 101-106. 